\title{
Housing and communal services as a factor of the urban sustainability
}

\author{
Urpash Shalbolova ${ }^{1}$, Zarina Chikibayeva ${ }^{1}$, Saule Yegemberdiyeva ${ }^{1}$, and Yevgeniy Kim $^{2}$ \\ ${ }^{1}$ L.N. Gumilyov Eurasian National University, Satpaev street, 1, 010000 Nur-Sultan, Kazakhstan \\ ${ }^{2}$ Academy of Civil Service under the President of the Republic of Kazakhstan, Abay street, 33-a, \\ 010000 Nur-Sultan, Kazakhstan
}

\begin{abstract}
The article examines the influence of the housing and communal services on the sustainability of the city. The work provides the interpretation of the "urban sustainability" category, considers the main indicators of ensuring the sustainability of the city. The components of the urban sustainability, associated with the improvement and modernization of housing and communal services for the degree of comfort of living of the population, have been substantiated. The role of housing and communal services in ensuring the sustainability of the city, the sustainability of the urban environment is presented in the results of a survey conducted as part of a sociological study. The issues of the quality of the provided housing and communal services, the degree of satisfaction of consumers with housing and communal services, the extent to which residents can take part in making decisions to improve the quality of life and the urban environment, issues of safe life in the city, the need to build new social facilities to improve the urban environment, the degree of implementation of investment design solutions, organization of management of apartment buildings, etc. The study was carried out as part of a scientific project.
\end{abstract}

\section{Introduction}

People have always wanted to live in a sustainable city, the rural population have moved to the urban area, thereby promoting the urbanization process. In the modern world, there are quite a few urbanized cities that no longer geographically accommodate the growing urban population. As a result, the stability of the city decreases due to a lack of housing; spontaneous urban housing estates appear, providing no legal rights to residential real estate and no infrastructure facilities that meet modern requirements. Sometimes there are even no basic housing and communal services. This violates the ecology of the urban environment. Such urban settlements are difficult to manage by various government agencies. The Geneva Charter on Housing and Sustainable Urban Development considers such a phenomenon to be the main problem of modern large cities [1].

Modernization of housing and communal services and housing stock, improving the quality of infrastructural urban facilities, including for poor and informal urban settlements, correct planning of urban areas, preventing uncontrolled urban expansion, guaranteeing 
rights to own real estate for the urban population are the main directions of the economic Geneva charter [2].

World systems have quite a few historically formed cities with their own culture, with their own forms of government, utilities the sustainable cities coexist along with. Sustainable cities in their development strategies are based on a long-term forecast of territorial expansion using innovative technologies and investment projects. Prediction of the urban sustainability considers the management and development of the entire urban area, including both poor and quite successful prosperous residential areas. To manage a sustainable city, as a rule, an active part of the urban population is involved to make decisions on improving the city: building new social or housing infrastructure, modernizing housing and communal facilities, switching to a new management system for apartment buildings, etc. [3].

The use and legislative approval of various economic instruments of state policy for the construction of affordable housing for individual citizens included in the list of social groups in each individual country is of great importance for ensuring the sustainability of the urban environment. At the design stages and further, during the construction of residential buildings, multiple dwelling units, various conditions must be met for the comfortable living of different categories of people: large families, disabled, elderly people. Also, during the implementation of the national housing policy, the functioning of housing enterprises for the provision of utilities is monitored in terms of ensuring quantitative and qualitative indicators as factors for expanding a sustainable urban environment [4].

The study of the state of urban housing and communal services, the modernization of facilities for the provision of urban utilities are aspects of the level of comfortable living of the population, the sustainability of the urban environment and the city.

\section{Material and Methods}

The use of the theoretical method is based on the review of previously conducted research of economic relations in ensuring a sustainable city. The economic development of cities, their sustainability is the subject of research by S.A. Legostava, B.A. Kochurov, I.V. Ivashkina, T.M. Tokmurzin and Tosmacheva A.E., Ermolaeva E.M., Perkova M.V., Makeev V.A. [5-10]. Kruchinina E.B. and Radionov S.I. devoted their research to the assessment procedure of the sustainability and development potential of the city $[12,13]$. The international scientometric databases contain studies on the development of the urban potential and its infrastructure, such as the works by R.U. Rakhmetova and Slka D.N. [1416]. One of the factors of sustainability of a modern city is the introduction of digital technologies in the development of smart cities [17].

The method of analysis and synthesis of actual indicators made it possible to obtain evaluation criteria for the object of research. The research strategy was chosen as inductive, as the obtained results of observation and measurements ensured the most accurate analysis. The experimental research methodology was chosen in the form of a social survey by questioning respondents. The survey revealed the problematic issues of satisfaction of the urban population with the quality of housing and communal services, which, in turn, act as factors of the sustainability of a modern city. The used method of analysis allowed for a deeper consideration of all the individual processes of the research subject by dividing them into separate aspects. Both quantitative and qualitative aspects of the impact of housing and communal services on the stability of the city were identified. 


\section{Results and Discussion}

The place where people live for a long period of time in the harmony of the ecologically clean environment, good health, constant improvement of the quality of life of the population, is also a sustainable city. The concept of a sustainable city can have various interpretations depending on the traditions, history, culture of the geographical area of the city. Sustainable cities in the modern sense are a territory designed for improving interpersonal communication and inter-structural ties between local executive bodies, business, social sector and non-profit organizations in order to achieve innovative approaches to city management and urban excellence.

The sustainability of any city can be assessed by certain indicators. These include the number of housing stock commissioned for a certain period of time, the number of urban population, the number of newly arrived people to live in a particular city, the growth in investment in fixed assets of urban objects and buildings, the growth rate of the physical volume of urban fixed assets, the ecological state of the city, and the level of air pollution, the state of urban infrastructure and housing and communal services, the availability of social facilities (health, education, culture, sports) per the number of urban population, the situation with solid waste disposal, the level of crime, ensuring all types of city safety, the level of comfort and urban environment. As of September 1, 2018, the population of the Republic of Kazakhstan exceeds 18.76 million people, 11 million of which is the urban population, making $58.8 \%$ of the total number of the population [18]. In 1991, at the time of becoming a separate state, the population of Kazakhstan was 16.4 million. However, as a result of external migration, the population decreased by $10 \%$ from 1991 to 2002 . However, starting in 2002, due to natural population growth and the arrival of repatriates of indigenous nationality in the country for permanent residence from other countries (China, Mongolia, Turkey, Uzbekistan, Russia, etc.), the population began to grow gradually. Migrants, as a rule, choose big cities as their place of residence. As in the rest of the world, there is a migration of rural residents to cities in the country.

The economic development of large cities in Kazakhstan and higher level of living comfort attract people from rural areas and small towns to more favorable cities, such as Almaty, Astana, Shymkent, for employment. There are 87 cities in Kazakhstan, three of which have the status of republican significance, and 38 regional centers.

The formation of urban agglomerations, urbanization, the expansion of the housing stock, the growth of the urban population are the components of the sustainability of cities in the Republic of Kazakhstan. An urbanized city, as a rule, faces problems that require constant monitoring and solution. Often these are the physical deterioration of housing and communal infrastructure facilities, the lack of innovative technologies and an automated system for the supply of communal services. Another problem is the lack of the use of new composite and environmentally friendly building materials in the construction of various objects and buildings for housing, civil, and social purposes.

The current state of the urban housing and communal services industry indicates the presence of still unresolved issues and problems in the management of housing and communal services, which is characterized by a level of resource losses, a high accident rate of fixed assets, and technological backwardness. The use of innovative energy supply technologies, the expansion of the introduction of green technologies contributes to the sustainability of a modern city.

One of the priorities and pressing issues of a modern city that ensures its sustainability is the supply of clean water to the apartment of every city dweller. Its solution requires a constant diagnostics of water supply networks and their maintenance systems, the use of environmental water treatment methods, innovative technologies for the protection of 
underground water pipelines and communications, the use of reliable and durable materials in the production of water supply pipes.

In market conditions, pricing of the supply of utilities is important; sometimes prices for services may be different depending on the service provider. This situation gives rise to the need to regulate the cost of basic housing and communal services at the state and city levels. An analytical review of the current state of urban housing and communal services in individual cities of Kazakhstan made it possible to identify a number of problems affecting the sustainability of the city (Table 1).

Table 1. The key operation problems of the urban housing and communal services in Kazakhstan

\begin{tabular}{|l|l|l|}
\hline No. & Sub-sectors & Problems \\
\hline 1 & $\begin{array}{l}\text { Power supply, } \\
\text { heat supply }\end{array}$ & $\begin{array}{l}\text { Underwork of power equipment and facilities, loss of electricity and } \\
\text { heat, low automation of production processes, poor thermal insulation. }\end{array}$ \\
\hline 2 & $\begin{array}{l}\text { Water supply } \\
\text { and discharge }\end{array}$ & $\begin{array}{l}\text { Water loss during water distribution in different directions, physical } \\
\text { deterioration of water supply networks and pipes, frequent accidents } \\
\text { and poor organization of repair work. }\end{array}$ \\
\hline 3 & $\begin{array}{l}\text { Streets and } \\
\text { sidewalks } \\
\text { cleaning }\end{array}$ & $\begin{array}{l}\text { Organization of manual cleaning of streets and sidewalks, low } \\
\text { provision with mechanized machines and equipment, low provision } \\
\text { with street storm drains }\end{array}$ \\
\hline 4 & $\begin{array}{l}\text { Street lighting } \\
\text { Waste use of street lighting, its physical deterioration, lack of } \\
\text { innovative sources of electric lighting. }\end{array}$ \\
\hline 5 & $\begin{array}{l}\text { Payment for } \\
\text { provided }\end{array}$ & $\begin{array}{l}\text { The presence of cases of insolvency, lack of unified payment } \\
\text { acceptance system between utility companies, weak digitalization of } \\
\text { utility payment process. }\end{array}$ \\
\hline
\end{tabular}

A degree of satisfaction by the population with the quality of housing and communal services provided has a significant effect on the level of sustainability of the urban environment. To identify the level of satisfaction with the quality of the provided public services, sociological surveys of the population were carried out in a number of cities of the Republic of Kazakhstan, which identified the main problems in the activities of both housing and communal, and municipal services.

The purpose of the sociological study was to assess the work of the housing and communal services and municipal services in order to substantiate recommendations on the socio-economic prerequisites for the modernization of housing and communal facilities and the organization of urban management. The sociological questionnaire contained 24 questions concerning evaluation of the work of organizations providing housing and communal services; problems of urban housing and communal services; participation of the population in events held by cooperatives of apartment owners; the most frequently used services of housing and communal services; degree of satisfaction/dissatisfaction with the work of housing and communal enterprises; value for money in terms of the received utilities and their price; safety issues for residents of apartment buildings; solutions to reduce the cost of housing and communal services; issues of organizing parking spaces in residential buildings; the need to create new social, cultural, and sports facilities for urban residents; the degree of implementation of the proposals of residents by the organizations of housing and communal services; changes proposed by the population in the work of housing and communal enterprises. The results of a sociological survey for the quality of housing and communal services are presented in Table 2. 
Table 2. Assessment of the quality of housing and communal services by urban residents

\begin{tabular}{|l|c|c|}
\hline \multicolumn{1}{|c|}{ Rate } & Number of people & $\%$ \\
\hline Excellent & 39 & 8.2 \\
\hline Good & 219 & 45.9 \\
\hline Satisfactory & 90 & 18.9 \\
\hline Unsatisfactory & - & - \\
\hline Difficult to answer & 97 & 6.7 \\
\hline $\begin{array}{l}\text { The house is not serviced by a managing } \\
\text { company }\end{array}$ & 477 & 100 \\
\hline Total: & & 20.3 \\
\hline
\end{tabular}

Sociological questioning of the urban population usually reveals broader problems, many of which are complaints about the quality of work of housing and communal enterprises. They are divided into two main groups: the degree of work of housing and communal enterprises, and complaints about the work of cooperatives of apartment owners. The first is the quality of the elevator facilities, since there have been facts of their poor operation, and sometimes their collapse. Quite a lot of complaints were raised about the quality of work of water supply companies (no water pressure on the upper floors in multiple dwelling units, no hot water supply). As for the heat supply, there were complaints about the lack of or insufficient heat in the winter period. The second group includes the issues of physical deterioration of residential buildings, the lack of repair work (repair of the roof, exterior cladding of the facade of houses), unequipped children's playing grounds and other courtyards, poor landscaping of streets and courtyards, outdated sanitation and cleaning of common areas of use in multiple dwelling units, etc. The city dwellers cannot always solve the first part of the problematic issues themselves, without the intervention of the city administration. To solve the second-block problems in Kazakhstan, the forms of self-management of multiple dwelling units are currently being reorganized - the transition in housing management from cooperatives of apartment owners (CAO) to an association of property owners (APO). The difference is that CAO is a management company, which can spend the entire budget for the maintenance of houses on a large residential complex consisting of several residential buildings, while the APO will be created by the residents of only one dwelling unit, regardless of its inclusion in some residential complex.

Consumers have often turned to the relevant organizations of housing and communal services to provide them with the following services: adding funds to the elevator card; cleaning the entrance; waste disposal; water problems; calling an electrician; repairing the entrance; arranging a playground, etc. To solve these problems, a significant obstacle in terms of improving the quality of provided utilities is the lack of motivating factors for housing and communal services in terms of the introduction of modern technologies, which is due the lack of both mechanisms to promote the technological modernization of this sector, and restrictions on the solvency of demand.

The results of the survey of the urban population of Kazakhstan regarding their application or complaint to the relevant housing and communal service show that $62 \%$ of respondents are satisfied with the result, and 38\% did not get the desired result. In the course of the study, the degree of consumer satisfaction with the work of the housing and communal service that manages their house (Table 3 ). 
Table 3. Assessment of satisfaction of urban residents with the work of their housing and communal services

\begin{tabular}{|c|c|c|}
\hline Rate & Number of people & $\%$ \\
\hline $0-30 \%$ (unsatisfactory) & 170 & 35.6 \\
\hline $31-60 \%$ (satisfactory) & 184 & 38.6 \\
\hline $61-100 \%$ (excellent) & 19 & 4.0 \\
\hline Difficult to answer & 7 & 1.5 \\
\hline The house is not serviced by a managing company & 97 & 20.3 \\
\hline Total & 477 & 100 \\
\hline
\end{tabular}

According to the results of the questionnaire survey, $38.6 \%$ of the respondents are satisfied with the work of the relevant housing and communal services, $35.6 \%$ of the population are not satisfied, $4.0 \%$ rated the work of these organizations as "excellent", $20.3 \%$ of the respondents noted that their house is not serviced by the managing company, and $1.5 \%$ found it difficult to answer.

Among the measures to change the work of housing and communal services, respondents noted cleaning of the territory, constant monitoring of cleanliness in the entrances, landscaping, change of the service company, improvement of playgrounds, installation of sports equipment, cleaning of entrances, landscaping, quality of services, control over the services provided, consistency, periodic repair of entrances and facades.

One of the most important budget items of any urban family is the payment of received utilities and housing services. According to the results of the sociological survey, $45.7 \%$ of the respondents consider payment for received housing and communal services quite justified, while the majority $-54.3 \%$, on the contrary, are dissatisfied with the prices and tariffs in the bills for housing and communal services (Fig. 1)).

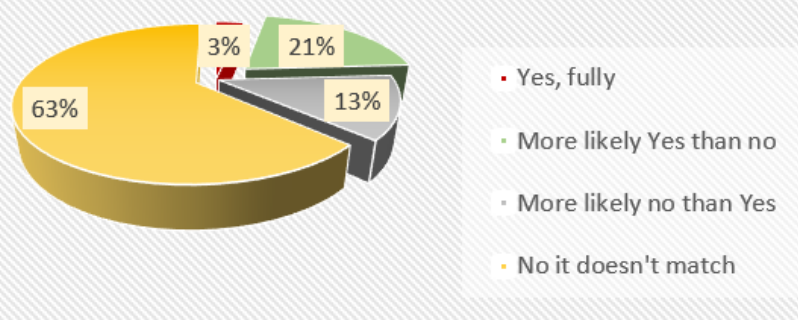

Fig. 1. Degree of justification of payment for the provided housing and communal services

The surveyed urban residents of multiple dwelling units do not always agree with that payment for the maintenance of a house includes only common communal technological objects, which, as a rule, are located in the basements of residential buildings. Everything located inside the apartment should be maintained only by the residents themselves (repair of plumbing work, electrical supply devices). The survey results are presented in Table 4.

Table 4. Assessment of the safety of residents.

\begin{tabular}{|c|c|c|}
\hline Safety state & Number of people & $\%$ \\
\hline Unsatisfactory & 124 & 26 \\
\hline Satisfactory & 268 & 56.2 \\
\hline Excellent & 85 & 17.8 \\
\hline Total & 477 & 100 \\
\hline
\end{tabular}

Table 4 shows that $56.2 \%$ of residents consider the state of safety in the residential houses satisfactory, $26.0 \%$ - unsatisfactory, and $17.8 \%$ - excellent. 
Among the measures to reduce the cost of energy and water supply, heating, ventilation and protection systems, respondents noted joint servicing, independent choice of these organizations by residents, economical use of funds, installation of meters, making a common decision at meetings with residents, reduction of taxes, use of services of different companies, use of new meters, the ability for residents to choose companies for the maintenance of residential buildings themselves, and economical use of resources.

More than half of the residents answered satisfactorily to the question of whether they could resolve the problems associated with the provision of housing and communal services themselves (Fig. 2).

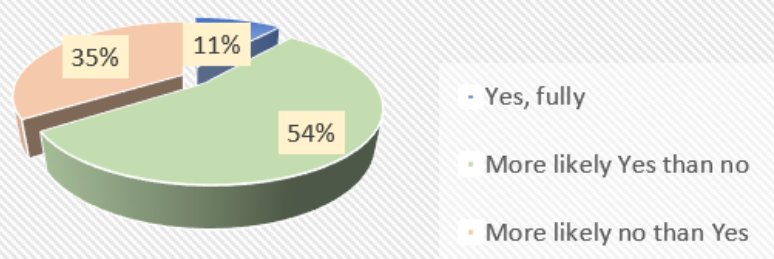

Fig. 2. Assessment of the solutions to problems associated with the provision of housing and communal services

To improve the services provided by the housing and communal services, the respondents suggested the following changes: equipment of buildings with voice assistants, automation of all systems, improvement of infrastructure, elimination of problems with hot water and water supply to the upper floors, a change in the entire structure of housing and communal services, improvement of service quality, automation of all services, transparency of deducted payments, installation of the latest technology, digitalization, modern technologies, and contactless service.

\section{Conclusion}

The quality of life of the urban population is always compared with the degree of satisfaction with the provided paid utilities and housing services. The maintenance of urban housing and communal facilities, although transferred to a competitive company, is still regulated by city administrative bodies because housing and communal services, as a sphere of the economy, is part of a socially significant industry.

Modernization of housing and communal services in Kazakhstan is solved at the government level through the implementation of relevant state programs for the development of urban areas, demolition of dilapidated housing, replacement of outdated equipment of municipal life support systems of the city, the introduction of innovative technologies, management through digital payment schemes and economic tools, the use of the experience of foreign countries in sorting and processing of solid household waste, introduction of a project management method for urban housing and communal services, creation of comfortable urban recreation areas, implementation of a green economy and green city program. Such effective and efficient programs have already begun to take effect in the country.

One of the main areas of urban sustainability in Kazakhstan has been implemented in recent years through the modernization, namely digitalization of housing and communal services. All cities of Kazakhstan are applying standards of construction safety and housing and communal relations. Also, great importance is attached to the introduction of the concept of 
urban safety. Large countries are implementing programs that have received the prefix "smart" (home, management, urban environment, recreation areas, etc.) [17].

\section{Acknowledgements}

The article was prepared based on the results of research carried out within the framework of a scientific project funded by the Science Committee of the Ministry of Education and Science of the Republic of Kazakhstan No. AP05134552 "Economic evaluation of investment projects to modernize the housing and communal services of the Republic of Kazakhstan".

\section{References}

1. Nations, Habitat III Issues Papers; No 20- Housing, United Nations, New York: United Nations, (2015)

2. United Nations Conference on Housing and Sustainable Urban Development (Habitat III), Quito, 17 (2016) http://habitat3.org/

3. Teck-Hong., 2012 Teck-Hong. T., Housing Satisfaction in Medium- and High-Cost housing: The Case of Greater Kuala Lumpur, Malaysia, Habitat International, 36, 108 (2012)

4. Donald, O and Canty-Waldron, J. The Strategic Indigenous Housing Infrastructure Program. Post Review assessment (2010)

5. Legostaeva S.A., Education and science without borders: fundamental and applied research, 5, 29 (2017)

6. Kochurov B.A., Ivashkina I.V., Collection of Proceedings "The Earth Charter - a practical tool for solving fundamental problems of sustainable development", 25 (2016)

7. Tokmurzien T.M., Tolmacheva A.E., Nauchnaia Perspektiva, 10, 12 (2016)

8. Ermolaeva E.M., Economics, Sociology, and Law, 3, 20 (2016)

9. Perkova M.V., City management: theory and practice, 1(16), 83 (2015)

10. Makeev V.A., Modern scientific research and innovation, 6-4 (50), 18 (2015)

11. Kruchinina E.B., Ecological systems and devices, 3, 34 (2019)

12. Rodionov S.I., Bulletin of Moscow University of the Ministry of Internal Affairs of Russia, 9, 182 (2012)

13. Rakhmetova, R., Zhakenova, K., Issabekov, N., Andekina, R., Tazabekova, A., Theoretical and Empirical Researches in Urban Management, 13(4) (2018), https://www.researchgate.net/

14. Rakhmetova, R., Zhakenova, K., Abenova, K., Ryskulova, M., Andekina, R., Espacios - Received: 06/10/2017, http://www.revistaespacios.com/

15. Dmitriy Silka, Vadim Kankhva, MATEC Web of Conferences 106, 08031 (2017)

16. Urpash Shalbolova, Zita Kenzhegaliyeva, MATEC Web Conf., VI International Scientific Conference "Integration, Partnership and Innovation in Construction Science and Education" (IPICSE-2018), 251, 05042 (2018)

17. Population of Kazakhstan, https://ru.wikipedia.org/wiki/ 